\title{
OUT-OF-PILE MECHANICAL PERFORMANCE AND MICROSTRUCTURE OF RECRYSTALLIZED ZR-1.5 NB-O-S ALLOYS
}

\author{
S. KO, J. M. LEE, and S.I. HONG* \\ Department of Nanomaterials Engineering Chungnam National University \\ Daedok Science Town, Daejeon 305-764, Republic of Korea \\ "Corresponding author. E-mail : sihong@cnu.ac.kr
}

Received January 04, 2011

Accepted for Publication April 11, 2011

The out-of-pile mechanical performance and microstructure of recrystallized $\mathrm{Zr}-1.5 \mathrm{Nb}$-S alloy was investigated. The strength of the recrystallized $\mathrm{Zr}-1.5 \mathrm{Nb}-\mathrm{O}-\mathrm{S}$ alloys was observed to increase with the addition of sulfur over a wide temperature range, from room temperature up to $300^{\circ} \mathrm{C}$. A yield drop and stress serrations due to dynamic strain were observed at room temperature and $300^{\circ} \mathrm{C}$. Wavy and curved dislocations and loosely knit tangles were observed after strained to 0.07 at room temperature, suggesting that cross slip is easier. At $300^{\circ} \mathrm{C}$, however, dislocations were observed to be straight and aligned along the slip plane, suggesting that cross slip is rather difficult. At $300^{\circ} \mathrm{C}$, oxygen atoms are likely to exert a drag force on moving dislocations, intensifying the dynamic strain aging effect. Oxygen atoms segregated at partial dislocations of a screw dislocation with the edge component may hinder the cross slip, resulting in the rather straight dislocations distributed on the major slip planes. Recrystallized $\mathrm{Zr}-\mathrm{Nb}-\mathrm{S}$ alloys exhibited ductile fracture surfaces, supporting the beneficial effect of sulfur in zirconium alloys. Oxidation resistance in air was also found to be improved with the addition of sulfur in $\mathrm{Zr}-1.5 \mathrm{Nb}-\mathrm{O}$ alloys.

KEYWORDS : Zirconium Tube, Sulfur, Recrystallization, Oxidation, Mechanical Properties

\section{INTRODUCTION}

Zirconium alloys have been used as nuclear cladding materials because of their high temperature strength, corrosion resistance, good mechanical properties, and low neutron absorption [1]. Zr alloys' in-reactor behaviors (such as corrosion, mechanical strength, creep, and irradiation-induced growth) are mainly controlled by its alloying elements and thermo-mechanical processing during pilgering [2-4]. First generation zirconium alloys, such as Zircaloy-2 and Zircaloy-4, contain alloying elements such as $\mathrm{Sn}, \mathrm{Fe}$, and $\mathrm{Cr}$. These alloys have been used for several decades in nuclear reactors without any significant performance problems. However, efforts to enhance the safety and economy of nuclear power plants have led to the development of second generation $\mathrm{Zr}$ alloys, such as Zirlo $^{\mathrm{TM}}$ (trademark of Westinghouse Electric Co.), M5 ${ }^{\mathrm{TM}}$ (trademark of AREVA NP), and other advanced $\mathrm{Zr}$ alloys.

$\mathrm{Nb}$ and $\mathrm{Sn}$ are the important alloying elements in Zirlo $^{\mathrm{TM}}\left(\mathrm{Zr}-\mathrm{Nb}-\mathrm{Sn}-\mathrm{Fe}\right.$ base alloy) and M5 ${ }^{\mathrm{TM}}$ (Zr-Nb-O base alloy) tubes. Based on the in-reactor experience of various $\mathrm{Zr}$ alloys, it is generally found that $\mathrm{Sn}$ increases the mechanical strength and creep resistance, but decreases the corrosion resistance $[4,5]$. On the other hand, $\mathrm{Nb}$ increases the corrosion and irradiation-induced growth resistance [4]. It has also been found that the higher heat treatment temperature after the final pilgering step lowered the mechanical strength but enhanced the corrosion and growth resistance [5]. Therefore, stressrelieved claddings may be favored if relatively higher mechanical strength is required, while fully recrystallized cladding is favored if better corrosion and growth resistance are needed $[4,5]$.

One interesting and surprising observation of $\mathrm{Zr}$ base alloys is that the addition of as little as $25 \mathrm{ppm}$ of sulfur enhanced the mechanical strength, creep resistance, and corrosion resistance $[6,7]$. Sulfur and phosphorus have been known to cause embrittlement in many alloys by reducing the boundary cohesive strength [8-10]. The surprising result that resistance to thermal creep can be drastically improved by adding sulfur [9] has been almost unnoticed outside the nuclear industry and the nuclear-related academic community. At $400^{\circ} \mathrm{C}$, the addition of $25 \mathrm{ppm}$ sulfur is known to reduce the creep 
KO et al., Out-of-pile Mechanical Performance and Microstructure of Recrystallized Zr-1.5 Nb-0-S Alloys

Table 1. Chemical Compositions of $\mathrm{Zr}-1.5 \mathrm{Nb}-\mathrm{O}$ and $\mathrm{Zr}-1.5 \mathrm{Nb}-\mathrm{O}-\mathrm{S}$ - Alloys (by weight)

\begin{tabular}{c|c|c|c|c|c}
\hline & $\mathrm{Nb}(\%)$ & $\mathrm{Fe}(\mathrm{ppm})$ & $\mathrm{O}(\mathrm{ppm})$ & $\mathrm{S}(\mathrm{ppm})$ & $\mathrm{Zr}$ \\
\hline $\mathrm{Zr}-1.5 \mathrm{Nb}-\mathrm{O}$ & 1.56 & 272 & 1530 & $<5$ & balance \\
\hline $\mathrm{Zr}-1.5 \mathrm{Nb}-\mathrm{O}-25 \mathrm{ppm} \mathrm{S}$ & 1.57 & 327 & 1580 & 26 & balance \\
\hline $\mathrm{Zr}-1.5 \mathrm{Nb}-\mathrm{O}-160 \mathrm{ppm} \mathrm{S}$ & 1.52 & 412 & 1610 & 158 & balance \\
\hline
\end{tabular}

Table 2. Strain Rate Sensitivityof Zr-1.5 Nb-O and Zr-1.5 Nb-O-S-Alloys

\begin{tabular}{c|c|c}
\hline & Strain rate sensitivity (RT) & Strain rate sensitivity $\left(300^{\circ} \mathrm{C}\right)$ \\
\hline $\mathrm{Zr}-1.5 \mathrm{Nb}-\mathrm{O}$ & 0.0204 & 0.0185 \\
\hline $\mathrm{Zr}-1.5 \mathrm{Nb}-\mathrm{O}-25 \mathrm{ppm} \mathrm{S}$ & 0.0193 & 0.0197 \\
\hline $\mathrm{Zr}-1.5 \mathrm{Nb}-\mathrm{O}-160 \mathrm{ppm} \mathrm{S}$ & 0.0211 & 0.287 \\
\hline
\end{tabular}

rate of zirconium alloys by a factor of three $[9,10]$. Charquet [11] also reported that, at $400^{\circ} \mathrm{C}$, sulfur has an extremely beneficial effect on the steam corrosion resistance in zirconium alloys. Zirconium alloys containing sulfur have been patented $[10,12]$ and commercialized.

$\mathrm{Zr}-\mathrm{Nb}$ base alloys are known to have better corrosion resistance, but lower creep resistance, than $\mathrm{Zr}-\mathrm{Nb}-\mathrm{Sn}-\mathrm{Fe}$ alloys. Recent observation that both creep resistance and tensile strength were enhanced with the addition of a small amount of sulfur may lead to improved $\mathrm{Zr}$ - Nb base alloys. Ferrer et al. [6] observed that sulfur amplified many dynamic strain aging effects reputed to be due to oxygen, the yield stress plateau, strain rate sensitivity and ductility minimum, and the static aging peak. Chang and Hong [7] suggested that the deformation and strengthening mechanism for the deformation of $\mathrm{Zr}-\mathrm{Nb}-\mathrm{O}$ and $\mathrm{Zr}-\mathrm{Nb}-\mathrm{O}-\mathrm{S}$ alloys can best be explained by the dislocation interaction mechanism, in which the segregation of alloying elements affects the activation length of dislocations [9].

In this study, recrystallized $\mathrm{Zr}-1.5 \mathrm{Nb}-\mathrm{O}-\mathrm{S}$ alloys were designed for better mechanical strength and corrosion resistance than commercially available $\mathrm{Zr}-1 \mathrm{Nb}$ alloys, and their properties were characterized. Since $\mathrm{Zr}-1 \mathrm{Nb}-\mathrm{O}$ alloys have lower creep resistance than $\mathrm{Zr}-1 \mathrm{Nb}-0.8 \mathrm{Sn}-0.1$ $\mathrm{Fe}$ alloys, $\mathrm{Zr}-1.5 \mathrm{Nb}$ alloys with higher $\mathrm{Nb}$ and oxygen contents and a lower sulfur content ( $\mathrm{Zr}-1.5 \mathrm{Nb}-\mathrm{O}-\mathrm{S}$ alloys) were used for enhanced mechanical performance. Creep resistance and mechanical strength are both expected to be enhanced by increasing the both the $\mathrm{Nb}$ content (to $1.5 \mathrm{wt}$. $\%$ higher than that of typical $\mathrm{Zr}-1 \mathrm{Nb}-\mathrm{O}$ cladding tube alloys) and the oxygen content (of 1570 1610 ppm, which is near the higher end of the typical oxygen content in commercial $\mathrm{Zr}$ alloys). The higher oxygen content is also anticipated to amplify the effect of sulfur on the oxygen strengthening. The primary objective of this study is to investigate the deformation and fracture behaviors of recrystallized $\mathrm{Zr}-1.5 \mathrm{Nb}-\mathrm{O}-\mathrm{S}$ alloys and compare them to those of commercially available $\mathrm{Zr}$ alloys (such as $\mathrm{Zr}$ $1 \mathrm{Nb}-\mathrm{O}$ alloy) for nuclear fuel claddings

\section{EXPERIMENTAL}

Vacuum arc melting was used to cast $\mathrm{Zr}-1.5 \mathrm{wt}$. \% $\mathrm{Nb}-\mathrm{O}$ alloys, both without and with various sulfur contents (25 ppm, $160 \mathrm{ppm}$ ). The sulfur was added to the melt in the form of iron sulfide. The chemical compositions of the $\mathrm{Zr}-1.5 \mathrm{Nb}-\mathrm{O}$ and $\mathrm{Zr}-1.5 \mathrm{Nb}-\mathrm{O}-\mathrm{S}$ alloys are summarized in Table 1. The disk-shaped ingots (15 mm thick) were $\beta$-quenched (maintained at $1020^{\circ} \mathrm{C}$ for $0.5 \mathrm{hr}$ and quenched to water at room temperature), hot-rolled at $580^{\circ} \mathrm{C}$, annealed at $580^{\circ} \mathrm{C}$ for $3 \mathrm{hrs}$, and cold-rolled into $0.9 \mathrm{~mm}$ thick plates, with three intermediate heat treatments at $570^{\circ} \mathrm{C}$ for $2 \mathrm{hrs}$ each. During the final cold-rolling process, the thickness of the plates was reduced from $1.76 \mathrm{~mm}$ to $0.90 \mathrm{~mm}$. After the final cold rolling, the rolled samples were recrystallized at $580^{\circ} \mathrm{C}$ for $3 \mathrm{hrs}$.

Tensile testing was performed using a united testing machine (SFP 10), with the stress axis parallel to the rolling direction. Strain jump tests were performed at room temperature and $300^{\circ} \mathrm{C}$ to obtain the strain rate sensitivity. For the strain jump tests, the samples were initially strained at the rate of $10^{-4} / \mathrm{sec}$., and the strain rate was changed to $10^{-2} / \mathrm{sec}$. at the plastic strain of 0.025 . Oxidation tests were performed in air at $300^{\circ} \mathrm{C}$.

\section{RESULTS AND DISCUSSION}

In order to examine the effect of sulfur on the initial microstructure of recrystallized $\mathrm{Zr}-1.5 \% \mathrm{Nb}$ alloys, TEM observation was made on the $\mathrm{Zr}-1.5 \mathrm{Nb}-\mathrm{O}$ (both with and 


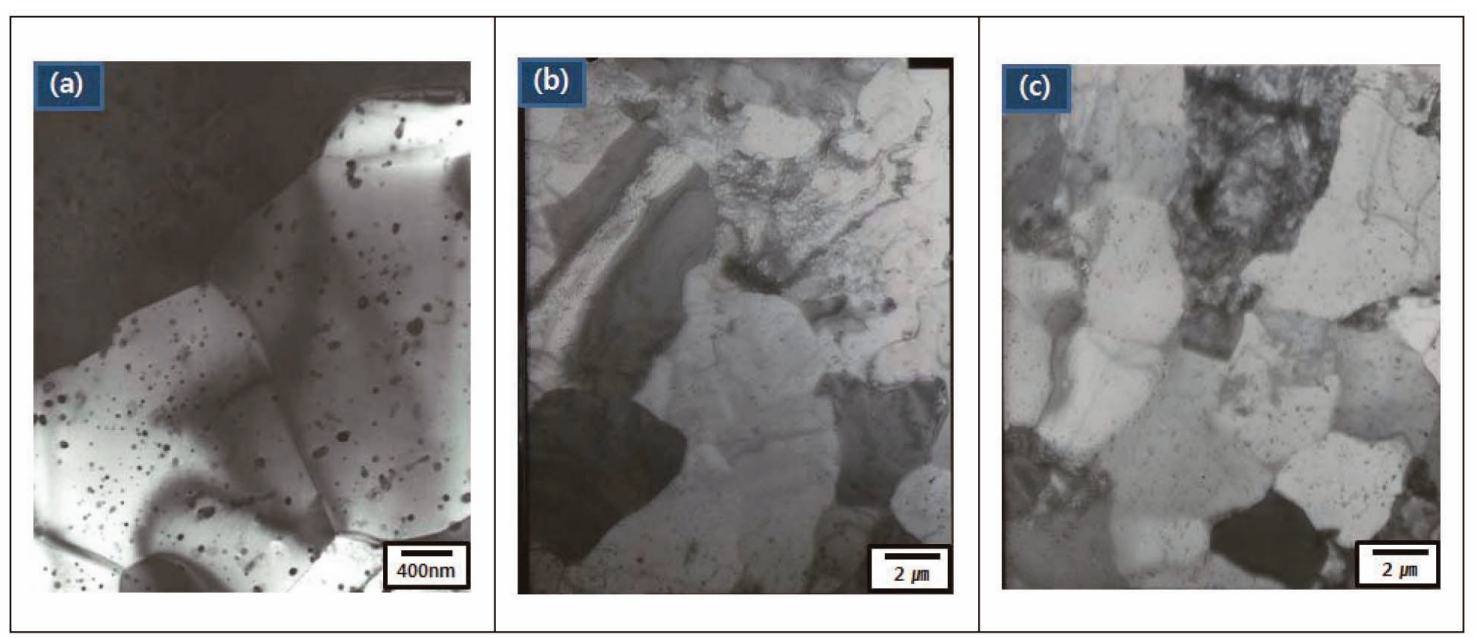

Fig. 1. TEM Micrographs of Recrystallized Zr-1.5Nb-O (a), Zr-1.5Nb-O-25 ppm S (b), and Zr-1.5Nb-O-160 ppm S (c).

without sulfur contents). Fig. 1(a), 1(b), and 1(c) display the TEM micrographs, as follows: Fig. 1(a) shows the recrystallized $\mathrm{Zr}-1.5 \mathrm{Nb}-\mathrm{O}$; Fig. 1(b) shows the recrystallized $\mathrm{Zr}-1.5 \mathrm{Nb}-\mathrm{O}-25 \mathrm{ppm} \mathrm{S}$; and Fig. 1(c) shows the recrystallized $\mathrm{Zr}-1.5 \mathrm{Nb}-\mathrm{O}-160 \mathrm{ppm} \mathrm{S}$. An equi-axed grain structure was observed in the recrystallized alloys, and the addition of sulfur was found to have an insignificant influence on the general microstructure. The sulfur had no observable effect on the grain size, which was up to $5 \mu \mathrm{m}$. X-ray diffraction pattern analysis did not display any peak from sulfur-containing compounds such as iron sulfide, zirconium sulfide, and niobium sulfide, which is likely due to the low sulfur content. EDS analysis revealed that the small, round particles in Fig. 1 are Fe-containing intermetallics, and the rod-shaped particles are $\beta-\mathrm{Nb}$ [13].

Figure 2 shows the stress-strain responses of recrystallized $\mathrm{Zr}-1.5 \mathrm{Nb}-\mathrm{O}$ (both without and with sulfur contents, $25 \mathrm{ppm}$ and $160 \mathrm{ppm}$ ) at both room temperature and $300^{\circ} \mathrm{C}$. In the recrystallized $\mathrm{Zr}-1.5 \mathrm{Nb}-\mathrm{O}$ alloys, the flow stress increased by $45 \mathrm{MPa}$ at room temperature with the addition of $25 \mathrm{ppm}$ sulfur. As the sulfur content was increased up to $160 \mathrm{ppm}$, the flow stress increased by $\sim 150 \mathrm{MPa}$. At $300^{\circ} \mathrm{C}$, the flow stress also increased by $\sim 70 \mathrm{MPa}$ with the addition of 160 ppm sulfur. A significant increase of flow stress was observed as the sulfur content of the recrystallized $\mathrm{Zr}-1.5 \mathrm{Nb}-\mathrm{O}$ was increased from 25 ppm to $160 \mathrm{ppm}$, unlike in the cold rolled $\mathrm{Zr}-1.5 \mathrm{Nb}-\mathrm{O}$. A yield drop was observed in the $\mathrm{Zr}-1.5 \mathrm{Nb}-\mathrm{O}$ and $\mathrm{Zr}-1.5$ $\mathrm{Nb}-\mathrm{O}-\mathrm{S}$ alloys, which became more pronounced with the addition of sulfur atoms. The addition of sulfur slightly reduced the ductility at both room temperature and $300^{\circ} \mathrm{C}$. Because of the dynamic strain aging at $200 \sim 400^{\circ} \mathrm{C}$, the ductility did not appreciably increase up to $300^{\circ} \mathrm{C}$, but it began to rapidly increase above $400^{\circ} \mathrm{C}$.

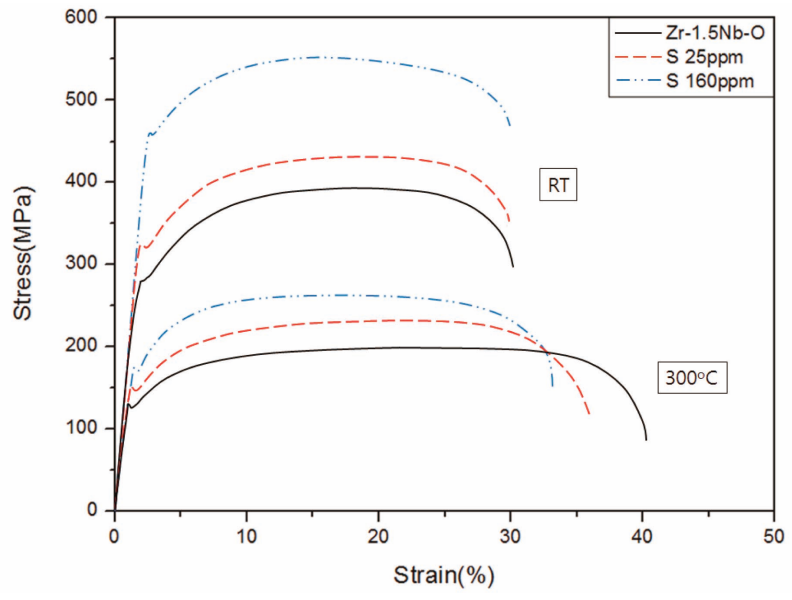

Fig. 2. Stress Strain Responses of Recrystallized Zr-1.5Nb-O without and with Sulfur Contents (25 ppm and $160 \mathrm{ppm})$ at Room Temperature and $300^{\circ} \mathrm{C}$.

Strain rate jump tests were performed to investigate the effect of strain rate in the recrystallized $\mathrm{Zr}-1.5 \mathrm{Nb}-\mathrm{O}$ and $\mathrm{Zr}-1.5 \mathrm{Nb}-\mathrm{O}-\mathrm{S}$ alloys, and the stress-strain behaviors of the strain jump tests are exhibited in Fig. 3. In the recrystallized $\mathrm{Zr}-1.5 \mathrm{Nb}-\mathrm{O}$ and $\mathrm{Zr}-1.5 \mathrm{Nb}-\mathrm{O}-\mathrm{S}$ alloys, stress jumps were observed during the strain rate jump from $10^{-4} / \mathrm{sec}$ to $10^{-2} / \mathrm{sec}$. It appears that the magnitude of the stress jumps became larger because of the increased strength level of the recrystallized alloys. The yield drops and stress serrations became more pronounced as the sulfur content was increased. The strain rate sensitivity was observed to increase slightly as the sulfur content was increased. 
Fig. 4 shows the TEM micrographs of the recrystallized $\mathrm{Zr}-1.5 \mathrm{Nb}-\mathrm{O}(\mathrm{a}, \mathrm{c})$ and $\mathrm{Zr}-1.5 \mathrm{Nb}-\mathrm{O}-160 \mathrm{ppm} \mathrm{S}(\mathrm{b}, \mathrm{d})$ alloys deformed to $7 \%$ strain at room temperature $(\mathrm{a}, \mathrm{b})$ and $300^{\circ} \mathrm{C}(\mathrm{c}, \mathrm{d})$. Particles in Fig. 4 were suggested to be $\beta-\mathrm{Nb}$ and Fe-containing intermetallics [13]. In the recrystallized alloys, wavy and curved dislocations and loosely knit tangles were observed at room temperature, suggesting an easier cross slip. At $300^{\circ} \mathrm{C}$, however, dislocations were observed to be straight and aligned along the slip plane, suggesting a more difficult cross

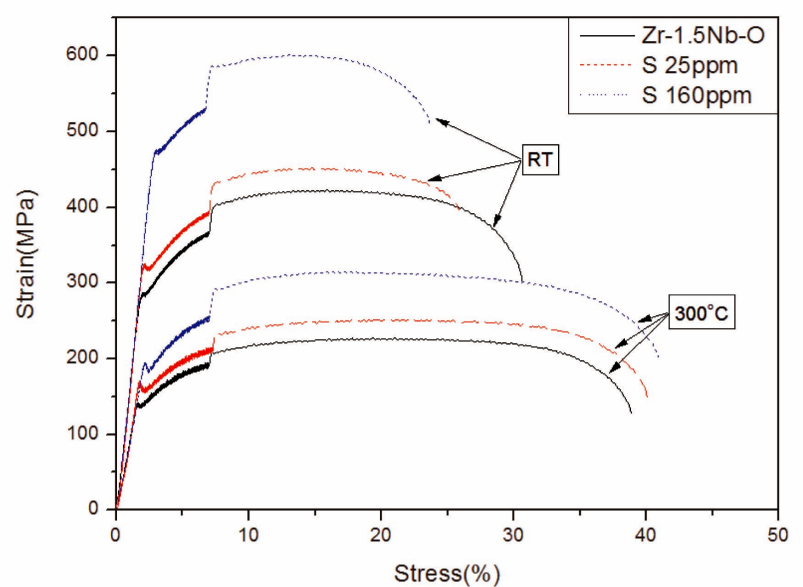

Fig. 3. Stress-strain Behaviors in Strain Jump Tests from 10-4 /sec to $10-2$ /sec in the Recrystallized $\mathrm{Zr}-1.5 \mathrm{Nb}-\mathrm{O}$ and $\mathrm{Zr}-1.5$ $\mathrm{Nb}-\mathrm{O}-\mathrm{S}$ Alloys. slip. At $300^{\circ} \mathrm{C}$, oxygen atoms are likely to exert a drag force on moving dislocations [14-16], thus intensifying the dynamic strain aging effect. Oxygen atoms segregated at partial dislocations of a screw dislocation with an edge component may hinder the cross slip [16, 17], resulting in rather straight dislocations distributed on the major slip planes.

Fig. 5 shows the TEM micrographs of the recrystallized $\mathrm{Zr}-1.5 \mathrm{Nb}-\mathrm{O}(\mathrm{a}, \mathrm{c})$ and $\mathrm{Zr}-1.5 \mathrm{Nb}-\mathrm{O}-160 \mathrm{ppm} \mathrm{S}(\mathrm{b}, \mathrm{d})$ alloys deformed until fracture at room temperature $(\mathrm{a}, \mathrm{b})$ and $300^{\circ} \mathrm{C}(\mathrm{c}, \mathrm{d})$. After straining until fracture at room temperature, the cold-rolled $\mathrm{Zr}-1.5 \mathrm{Nb}-\mathrm{O}$ and $\mathrm{Zr}-1.5 \mathrm{Nb}-$ O-160 ppm S alloys exhibited featureless high dislocation density with bending contours, suggesting significant dislocation storage and accumulation during deformation until fracture. At $300^{\circ} \mathrm{C}$, highly stored and tangled dislocations were observed, suggesting that the thermal activation and high local stress associated with high dislocation density induced cross slip and tangle-like dislocation morphology. The high dislocation density, however, implies that the recovery process is not fast enough to control the dislocation density. The effect of oxygen atoms on the dislocation motion are likely diminished as the dislocation density increases, because increasing dislocation density was accompanied by a drastic decrease in the number of oxygen atoms per dislocation.

Some solute atoms, such as $\mathrm{Si}$ and $\mathrm{Al}$, are known to amplify the dynamic strain aging effect due to interstitial atoms (including oxygen) in Ti alloys. Although such atoms cannot directly cause dynamic strain aging at
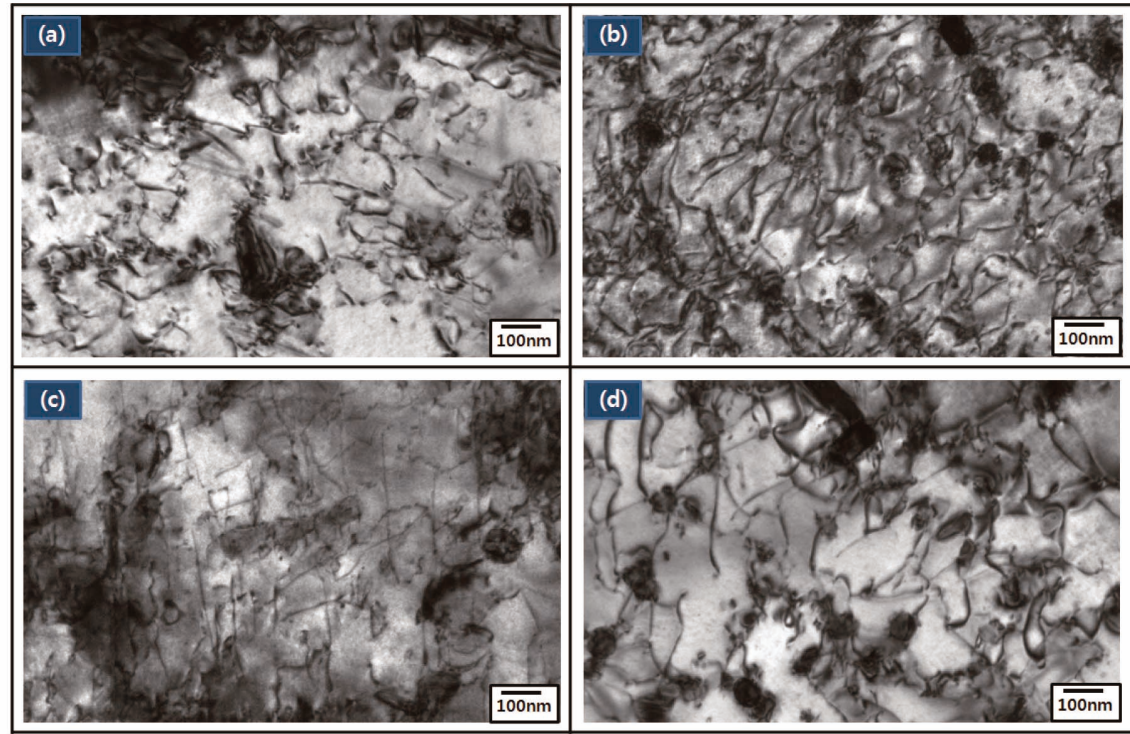

Fig. 4. TEM Micrographs of Recrystallized Zr-1.5Nb-O (a, c) and Zr-1.5Nb-O-160 ppm S (b, d) Alloys Deformed to $7 \%$ Strain at Room Temperature $(\mathrm{a}, \mathrm{b})$ and $300^{\circ} \mathrm{C}(\mathrm{c}, \mathrm{d})$. 
intermediate temperatures, they do enhance the lattice distortion [15, 16]. Ferrer et al. [12] observed that sulfur amplified many dynamic strain aging effects that were reputed to be due to oxygen, the yield stress plateau, the strain rate sensitivity and ductility minimum, and the static aging peak. Despite observations indicative of the amplification effect of sulfur on dynamic strain aging due to oxygen atoms, Ferrer et al. [12] suggested that the sulfur and oxygen effects are independent, based on their observation that sulfur's strengthening effect remained unchanged in the strain rate and temperature region in which dynamic strain aging due to oxygen disappeared. One important point overlooked by Ferrer et al. [12] is that oxygen strengthening consists of two parts: typical solution strengthening and strengthening due to dynamic strain aging. Even in the temperature and strain rate region in which dynamic strain aging effect is negligible, oxygen still strengthens the $\mathrm{Zr}$ matrix through regular solution strengthening. Some alloying elements could also experience both independent and interdependent strengthening effects.

Ferrer et al. [12] suggested that sulfur segregation at dislocation core could modify the core structure of dislocations, which would affect most dislocation properties, including Peierls friction, cross slip, pipe diffusion, and interaction with other impurities. However, in order for the modification of dislocation cores by sulfur to be an operative strengthening mechanism, the dislocation cores should be modified over a reasonable length of dislocations with the modified core structure maintained while dislocations are in motion during deformation. The mobility of sulfur atoms may not be high enough to keep up with moving dislocations in order to maintain the modified dislocation core structure during deformation. In Ferrer's model, if the dislocations are liberated from the segregated sulfur atoms, the modified core structure would return to its original structure and the Peierls friction may not be appreciable.

Chang and Hong [7] suggested that the rate-controlling mechanism for the deformation of $\mathrm{Zr}-\mathrm{Nb}$ and $\mathrm{Zr}-\mathrm{Nb}-\mathrm{S}$ alloys can be best explained by the dislocation interaction mechanism in which the segregation of alloying elements affects the activation length of dislocations [9]. The segregation of sulfur atoms in addition to oxygen atoms [21] could decrease the activation volume by limiting the length of the activated bulge, thereby enhancing the

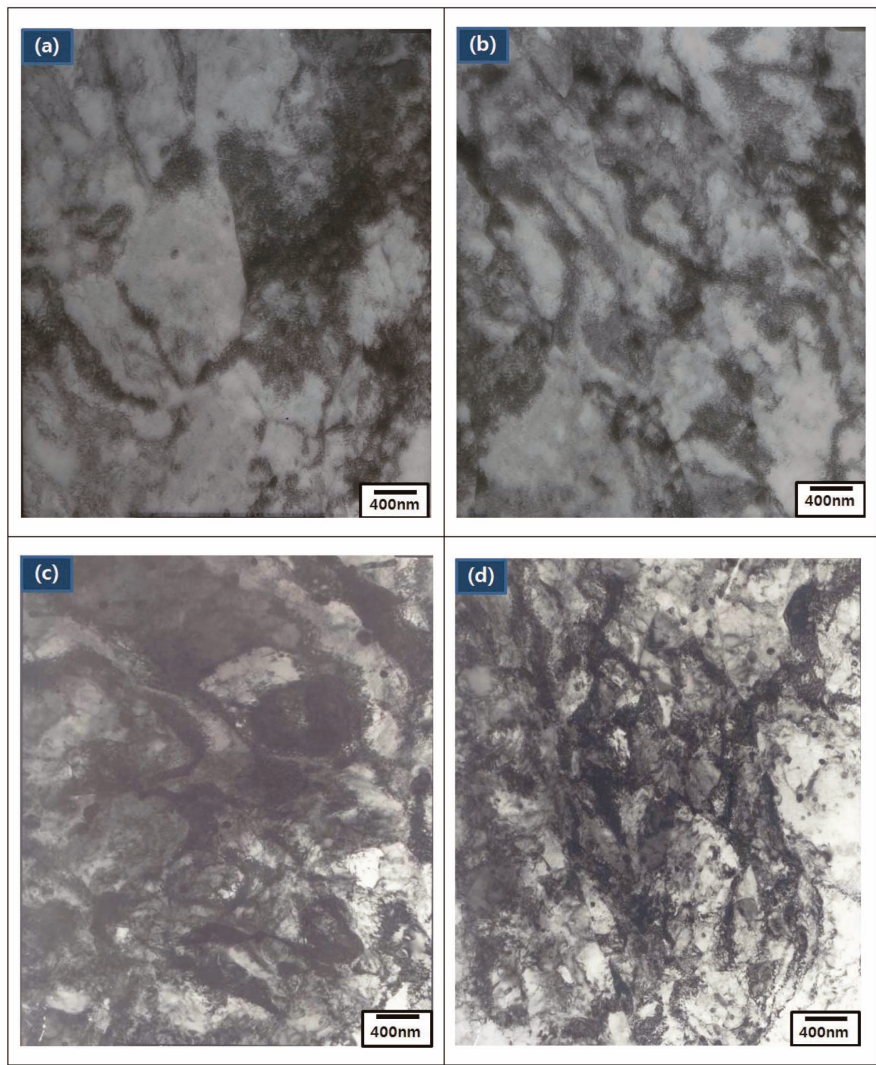

Fig. 5. TEM Micrographs of Recrystallized Zr-1.5Nb-O (a, c) and Zr-1.5Nb-O-160 ppm S (b, d) Alloys Deformed Until Fracture at Room Temperature $(\mathrm{a}, \mathrm{b})$ and $300^{\circ} \mathrm{C}(\mathrm{c}, \mathrm{d})$. 


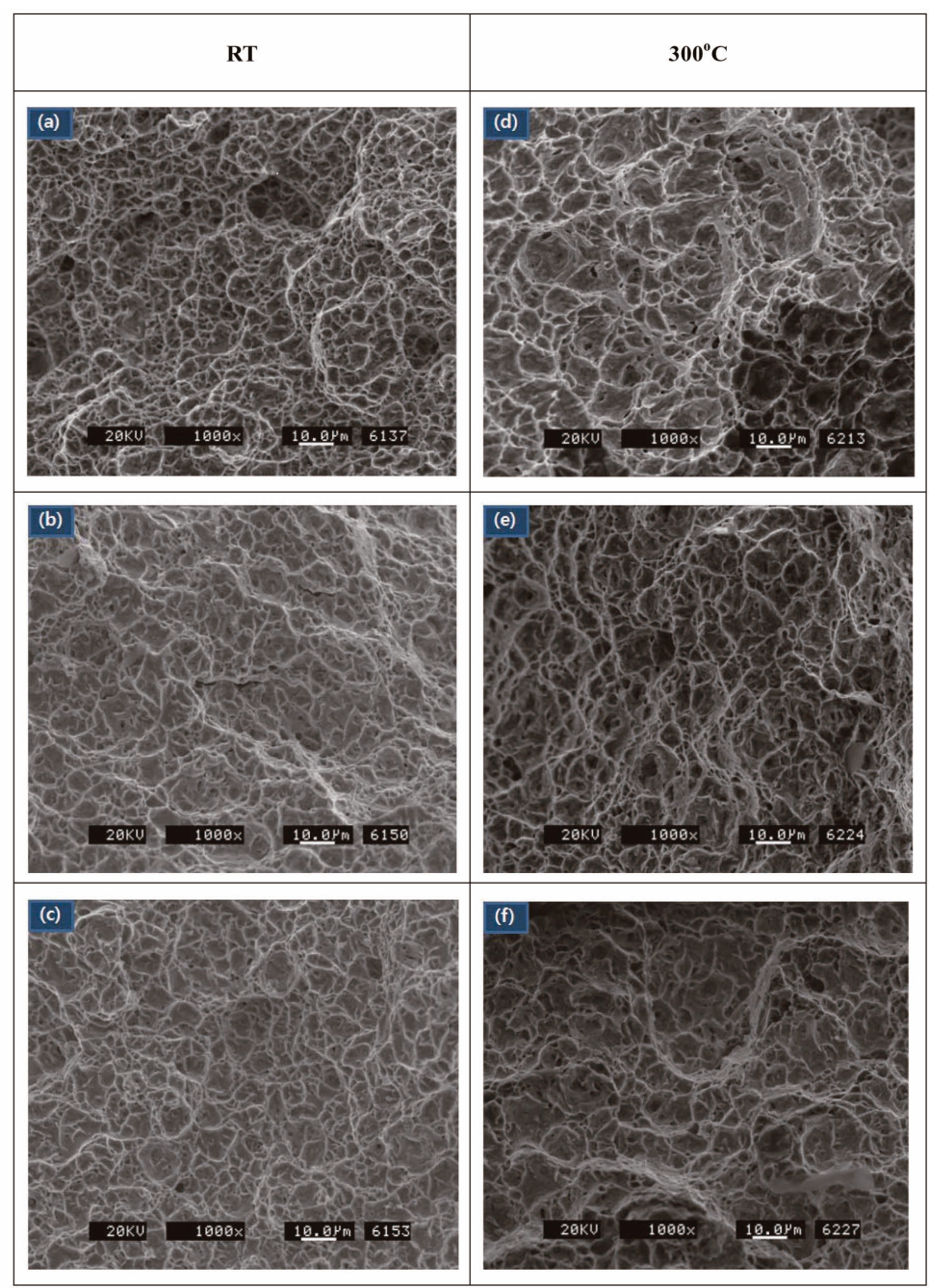

Fig. 6. Fracture Surfaces of Recrystallized $\mathrm{Zr}-1.5 \mathrm{Nb}-\mathrm{O}$ (a, d); $\mathrm{Zr}-1.5 \mathrm{Nb}-\mathrm{O}-25 \mathrm{ppm} \mathrm{S}$ (b, e); andZr-1.5Nb-O-160 ppm S (c, f) at Room Temperature $(\mathrm{a}, \mathrm{b}, \mathrm{c})$ and $300^{\circ} \mathrm{C}(\mathrm{d}, \mathrm{e}, \mathrm{f})$.

strengthening effect. The suggestion that the reduced length of the activated bulge of dislocations (which occurs due to the segregation of oxygen and sulfur atoms) is linked to the activation volume is supported by the fact that the activation volume is insensitive to the dislocation density and decreases at a higher temperature (where dynamic strain aging occurs). Even at low temperatures, dislocations can collect a significant number of solute atoms from their surroundings after being stopped by forest dislocations [9, 21].

Strengthening due to sulfur may arise from the disturbing effects of solute atoms on dislocation motion. The most important factors affecting dislocation motion in solution are the size factor, the modulus factor, and the electronic factor [18, 19]. Morinaga and Kamado [20] found that both solution hardening and precipitation hardening can best be predicted by the differences in size and electronegativity between the matrix and solute atoms. The atomic radius of sulfur is $0.106 \mathrm{~nm}$ and that of zirconium is $0.159 \mathrm{~nm}$, implying that the size factor has a great influence. Since the electronegativity of sulfur and zirconium are 2.58 and 1.33 (respectively), the electronegativity difference between $\mathrm{Zr}$ and $\mathrm{S}$ is 1.25 . Therefore, there would be appreciable electrostatic interaction due to the dipole creation between solute atoms and dislocation. Sulfur's significant strengthening effect can be ascribed to the differences in size and electronegativity between zirconium and sulfur.

Fig. 6 (a-f) shows the fracture surfaces of recrystallized $\mathrm{Zr}-1.5 \mathrm{Nb}-\mathrm{O}$ (a, d); $\mathrm{Zr}-1.5 \mathrm{Nb}-\mathrm{O}-25 \mathrm{ppm} \mathrm{S}$ (b, e); and $\mathrm{Zr}-1.5 \mathrm{Nb}-\mathrm{O}-160 \mathrm{ppm} \mathrm{S}$ (c, f), both after tensile testing at room temperature $(\mathrm{a}, \mathrm{b}, \mathrm{c})$ and $300^{\circ} \mathrm{C}(\mathrm{d}, \mathrm{e}, \mathrm{f})$. All 


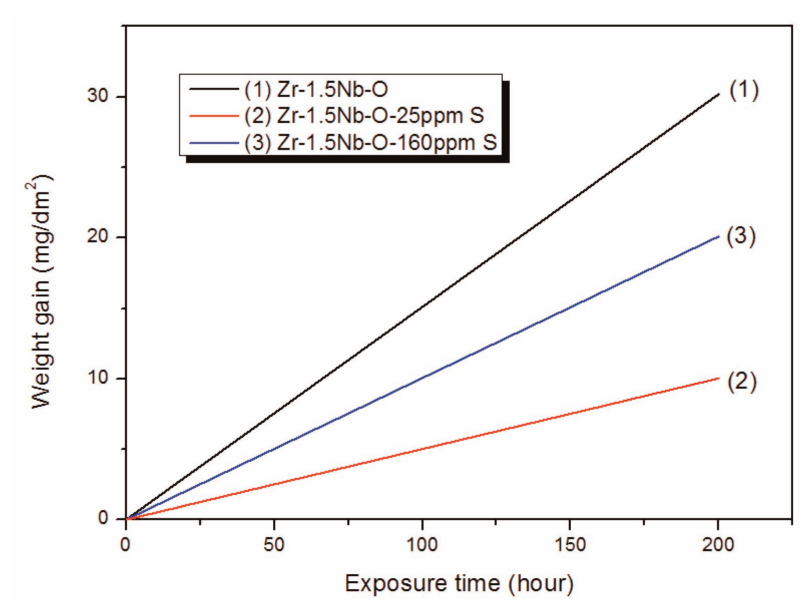

Fig. 7. Oxidation Behavior of Recrystallized $\mathrm{Zr}-1.5 \mathrm{Nb}-\mathrm{O}$, $\mathrm{Zr}-1.5 \mathrm{Nb}-\mathrm{O}-25 \mathrm{ppm} \mathrm{S}$, and $\mathrm{Zr}-1.5 \mathrm{Nb}-\mathrm{O}-160 \mathrm{ppm} \mathrm{S}$ in air at $300^{\circ} \mathrm{C}$.

alloys exhibited ductile fracture surfaces and no grooveor cleavage-like features [11] were observed, suggesting that the sulfur has no significant detrimental effect on the fracture of $\mathrm{Zr}-\mathrm{Nb}$ alloys. Also, no secondary cracks were observed. Similar ductile fracture surfaces were observed at $300^{\circ} \mathrm{C}$ for $\mathrm{Zr}-\mathrm{Nb}$ and $\mathrm{Zr}-\mathrm{Nb}-20 \mathrm{ppm} \mathrm{S}$. The absence of groove- or cleavage-like features on the fracture surface is compatible with the observation that $\mathrm{Zr}-\mathrm{Nb}$ alloys with the addition of $20 \mathrm{ppm}$ sulfur have no sulfide particles which may act as fracture paths, unlike Ti alloys [11].

Fig. 7 shows the oxidation behavior of recrystallized $\mathrm{Zr}-1.5 \mathrm{Nb}-\mathrm{O}, \mathrm{Zr}-1.5 \mathrm{Nb}-\mathrm{O}-25 \mathrm{ppm} \mathrm{S}$, and $\mathrm{Zr}-1.5 \mathrm{Nb}-\mathrm{O}-$ $160 \mathrm{ppm} S$ in air. The addition of sulfur resulted in less weight gain due to oxide formation. Charquet found that the addition of even a small amount of sulfur markedly improves the steam corrosion resistance, particularly in the range between 2 and $200 \mathrm{ppm}$. The beneficial influence of sulfur has been observed whether it is in solid solution or in the form of various sulfides. With the sulfides, the key factor is probably the volume fraction of the precipitates. However, the reason for the beneficial influence of sulfur is not yet understood. The sulfur may influence the phase and structural stability of oxide, but this remains to be solved in future work.

\section{CONCLUSIONS}

On the basis of this investigation of the mechanical and oxidation properties of $\mathrm{Zr}-1.5 \mathrm{Nb}-\mathrm{O}$ alloys, the following conclusions can be drawn:

1. The beneficial strengthening effect of sulfur was observed in the recrystallized $\mathrm{Zr}-1.5 \mathrm{Nb}-\mathrm{O}$ alloys over a wide temperature range, from room temperature up to $300^{\circ} \mathrm{C}$.
2. Yield drop and stress serrations due to dynamic strain were observed at room temperature and $300^{\circ} \mathrm{C}$. The effect of sulfur was amplified in the dynamic strain aging due to oxygen atoms, although it persisted over the whole temperature range.

3. Sulfur's significant strengthening effect can be ascribed to the differences in both size and electronegativity between zirconium and sulfur.

4. Wavy and curved dislocations and loosely knit tangles were observed after straining to 0.07 at room temperature, suggesting an easier cross slip. At $300^{\circ} \mathrm{C}$, however, dislocations were observed to be more or less straight and aligned along the slip plane, suggesting a rather difficult cross slip.

5. The recrystallized $\mathrm{Zr}-\mathrm{Nb}-\mathrm{S}$ alloys exhibited ductile fracture surfaces, thus supporting the beneficial effect of sulfur in zirconium alloys. Sulfur obviously does not cause any embrittlement in $\mathrm{Zr}$ and $\mathrm{Zr}$ base alloys.

6. Oxidation resistance in air was found to be improved with the addition of sulfur in $\mathrm{Zr}-1.5 \mathrm{Nb}-\mathrm{O}$ alloys.

\section{ACKNOWLEDGEMENTS}

This research was supported by the Basic Atomic Energy Research Institute Program through the National Research Foundation of Korea (NRF) and funded by the Ministry of Education, Science and Technology (20090075917).

\section{REFERENCES}

[1] J.A.L. Robertson, "Zirconium-an international nuclear material," J. Nucl. Mater., 100, 108 (1981).

[2] E. Tenckhoff and P.L. Rittenhouse, "Annealing textures in zircaloy tubing," J. Nucl. Mater., 35, 14 (1970).

[ 3 ] E.F Ibrahim, R. Choubey and J.J. Jonas, "Effect of texture and heat treatment on high temperature deformation of Zircaloy-2," J. Nucl. Mater., 126, 44 (1984).

[4] R.A. Holt, "Mechanisms of irradiation growth of alphazirconium alloys," J. Nucl. Mater., 159, 310(1988).

[ 5 ] W. Liu, Q. Li, B. Zhou, Q. Yan andM. Yao, "Effect of heat treatment on the microstructure and corrosion resistance of a Zr-Sn-Nb-Fe-Cr alloy," J. Nucl. Mater., 341, 97 (2005).

[6] D. Charquet, J. Senevat, J. P. Marcon, "Influence of sulfur content on the thermal creep of zirconium alloy tubes at $400^{\circ}$ C," J. Nucl. Mater., 255, 78 (1998).

[7] K. I. Chang and S. I. Hong, "Effect of sulphur on the strengthening of a $\mathrm{Zr}-\mathrm{Nb}$ alloy," J. Nuclear Mater., 373, 16 (2008).

[8 ] A.J. Stewart and M.W. Schmidt, "Sulfur and phosphorus in the Earth's core: The Fe-P-S system at $23 \mathrm{GPa}$," Geophys. Res. Lett., 34, L13201 (2007).

[9] D. Bika and C. J. McMahon Jr., "A model for dynamic embrittlement,” Acta Metall. Mater., 43, 1909 (1995).

[10] R. Wu, A. J. Freeman and G. B. Olson, "First Principles Determination of the Effects of Phosphorus and Boron on Iron Grain Boundary Cohesion," Science, 265, 376 (1994).

[11] D. Charquet, "Phase constitution and steam corrosion resistance of binary Zr-S alloys," J. Nucl. Mater., 304, 
246 (2002).

[12] F. Ferrer, A. Barbu, T. Bretheau, J. Crepin, F. Willaime and D. Charquet, "The Effect of Small Concentrations of Sulfur on the Plasticity of Zirconium Alloys at Intermediate Temperatures," In: ed. G.D. Moan and P. Rudling, ASTM STP., 1423, 863(2002).

[13] S. Ko, S. I. Hong and K. T. Kim, "Creep properties of annealed $\mathrm{Zr}-\mathrm{Nb}-\mathrm{O}$ and stress-relieved $\mathrm{Zr}-\mathrm{Nb}-\mathrm{Sn}-\mathrm{Fe}$ cladding tubes and their performance comparison," $J$. Nucl. Mater., 404, 154 (2010).

[14] S.I. Hong, W.S. Ryu, C.S. Rim, "Thermally activated deformation of Zircaloy-4,” J. Nucl. Mater.,120, 1(1984).

[15] S.I Hong, W.S. Ryu, C.S. Rim, "Elongation minimum and strain rate sensitivity minimum of zircaloy-4," J. Nucl. Mater., 116, 314(1983).
[16] S.I. Hong, "Influence of dynamic strain aging on the apparent activation energy for creep," Mater. Sci. Eng., 64, L19(1984).

[17] S. I. Hong and C. Laird, "Mechanisms of slip mode modification in F.C.C. solid solutions," Acta Metall. Mater., 38, 1581(1990).

[18] R.L. Fleischer, "Substitutional solution hardening," Acta Metall., 11, 203(1963).

[19] R.L. Fleischer, "Solution hardening," Acta Metall., 9, 996(1961).

[20] M. Morinaga and S. Kamado, "An electronic approach to the prediction of the mechanical properties of aluminum alloys," Modeling Simul. Mater. Sci. Eng., 1, 151(1993).

[21] M.J. Luton, J.J. Jonas, "Solute Strengthening at High Temperatures in Zirconium-Tin Alloys," Can. Metal. Quart. 11, 79(1972). 